\title{
Activation of miR-31 function in already-established metastases elicits metastatic regression
}

\author{
Scott Valastyan, ${ }^{1,2}$ Amelia Chang, ${ }^{1,2}$ Nathan Benaich, ${ }^{1}$ Ferenc Reinhardt, ${ }^{1}$ and Robert A. Weinberg ${ }^{1,2,3,4}$ \\ ${ }^{1}$ Whitehead Institute for Biomedical Research, Cambridge, Massachusetts 02142, USA; ${ }^{2}$ Department of Biology, Massachusetts \\ Institute of Technology, Cambridge, Massachusetts 02139, USA; ${ }^{3}$ Massachusetts Institute of Technology Ludwig Center for \\ Molecular Oncology, Cambridge, Massachusetts 02139, USA
}

Distant metastases, rather than the primary tumors from which these lesions arise, are esponsit for $>90 \%$ of carcinoma-associated mortality. Many patients already harbor disseminated tumor $11 \mathrm{~s}$ their $b$ bodstream, bone marrow, and distant organs when they initially present with cancer. Hence culy eft tive Gti-metastatic therapeutics must impair the proliferation and survival of already-established $r$ tasta $s$. $H$, we assess the therapeutic potential of acutely expressing the microRNA miR-31 in alread ion o breastcancer metastases. Activation of miR-31 in established metastases elicits metastatic regress and p long ourvival. Remarkably,

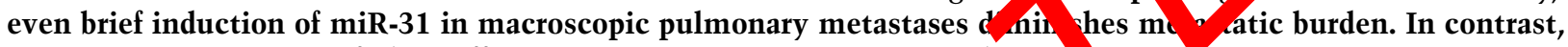
acute miR-31 expression fails to affect primary mammary tumor growth. $\mathrm{miR} 1$ triggers metastatic regression in the lungs by eliciting cell cycle arrest and apoptosis; these respor es occur spe fically in metastases and can be explained by miR-31-mediated suppression of integrin- $\alpha 5$, radixi , and RhoA. Indeed, concomitant re-expression of these three proteins renders already-seeded pulmonary metas ses refra tory to miR-31-conferred regression. Upon miR-31 activation, Akt-dependent signaling is attemated a the oapoptotic molecule Bim is induced; these effects occur in a metastasis-specific manner in pu to ary les and are abrogated by concurrent reexpression of integrin- 5 , radixin, and RhoA. Collectively the findings raise the possibility that intervention strategies centered on restoring miR-31 function a., prov anically useful for combating metastatic disease.

[Keywords: metastasis; miR-31; breast cancer metas ltic c onization; microRNA]

Supplemental material is available for thi artic

Received October 18, 2010; revised versior co ted Jan ry 31, 2011.

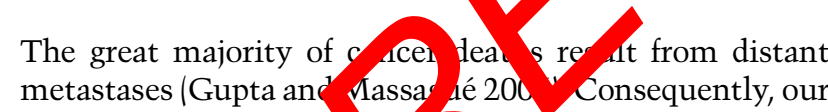
ability to significantly dy con ansociated mortality is dependent on preventil or reversing metastatic disease. Agents that effectively ta et any step of the invasionmetastasis cascade-the complex, multistep process whereby tumor cells disseminate from their primary site of growth and then survive and thrive in an ectopic microenvironment-should, in principle, be capable of diminishing the incidence of metastases (Fidler 2003; Gupta and Massagué 2006). However, clinical trials have indicated little anti-metastatic benefit conferred by compounds designed to block the escape of neoplastic cells from primary tumors (Steeg 2006; Smith and Theodorescu 2009). This is likely due to the fact that the precursor cells of overt metastases often have already disseminated to distant organ sites by the time of initial patient diagnosis

${ }^{4}$ Corresponding author.

E-MAIL weinberg@wi.mit.edu; FAX (617) 258-5213.

Article is online at http://www.genesdev.org/cgi/doi/10.1101/gad.2004211.
(Gupta and Massagué 2006; Nagrath et al. 2007; Pantel et al. 2008). Indeed, such cells may be capable of disseminating quite early during the course of tumor progression (Hüsemann et al. 2008).

These observations suggest that truly effective antimetastatic therapeutics must be capable of altering the behavior of already-disseminated tumor cells. Unfortunately, few examples of agents possessing these attributes have been identified. Instead, many anti-metastatic compounds currently in preclinical or clinical testing impede the initial dissemination of neoplastic cells without influencing the fate of established metastases (Steeg 2006; Smith and Theodorescu 2009/. For this reason, the development of novel therapeutics that impair the proliferation and survival of already-seeded metastases represents a topic of intense interest.

MicroRNAs (miRNAs) are crucial regulators of a variety of physiologic and pathologic processes, including tumor development and metastatic progression (Valastyan and Weinberg 2009; Ventura and Jacks 2009). One such miRNA involved in carcinoma pathogenesis, miR-31, functions as 
a pleiotropically acting suppressor of breast cancer metastasis. When constitutively expressed, miR-31 impairs at least three distinct steps of the invasion-metastasis cascade: local invasion, one or more early post-intravasation events (intraluminal viability, extravasation, and/or initial survival in the parenchyma of distant tissues), and metastatic colonization (the outgrowth of micrometastases into macroscopic secondary lesions) (Valastyan et al. 2009a,b). Hence, among other effects, constitutive miR-31 expression impedes the post-intravasation proliferation and survival of already-disseminated tumor cells. This prompted us to investigate whether acute activation of miR-31 in already-established breast cancer metastases might elicit anti-metastatic therapeutic responses in settings that mimic the circumstances encountered in clinically arising carcinomas.

\section{Results}

Acute miR-31 expression drives regression of established spontaneous lung metastases

In order to determine the consequences of expressing miR31 in a temporally controlled manner, we used a doxycycline (dox)-inducible miR-31 expression vector system (Supplemental Fig. 1A). As anticipated (Valastyan et al. 2009b), when these vectors were introduced into othervise metastatic MDA-MB-231 (231) human breast cancer which are essentially devoid of endogenous miR-31 exp ession (Valastyan et al. 2009b), we observed doy pend p inhibition of several in vitro cell biological t ness, motility, and resistance to anoik ed ce death) that serve as surrogate marker of in otationficiency (Supplemental Fig. 1B-D). ese eff ts arose in the absence of altered in vitro pulifo tion k etics and therefore did not represent costatic o cytotoxic influences (Supplemental Fig. 1\% These find gs established that our dox-inducible $s$, tem osely recapitulated the known influences of const ave mir-31 expression on malignant cellular

We exploited s abil y to p sely control the timing of miR-31 expres op corotive the impact of activating miR-31 function in ceady-seeded 231 cell lung metastases and primary tumors a various time points after implantation. Accordingly, we implanted the dox-inducible 231 cells orthotopically in the mammary fat pads of mice and activated miR-31 either (1) at no point during the experiment, (2) for the entire course of the 2-mo study, (3) only after relatively modest numbers of micrometastases had formed in the lungs at 1 mo post-implantation, (4) subsequent to the formation of large numbers of pulmonary metastases at $6 \mathrm{wk}$ after implantation, or (5) only following the establishment of an overwhelming metastatic burden in the lungs at $7 \mathrm{wk}$ post-implantation (Fig. 1A). The consequences of acute miR-31 expression on primary mammary tumor development and metastatic progression in the lungs were then assessed.

Activation of miR-31 at any of the assayed time points failed to alter 231 cell primary mammary tumor growth (Fig. 1B). The absence of an effect on primary tumor size did not arise due to failure of dox-mediated up-regulation of miR-31 (Supplemental Fig. 2). Moreover, the miR-31 molecules produced upon dox treatment were indeed functionally active, as gauged by their ability to suppress the levels of three known (Valastyan et al. 2009b) miR-31 downstream target genes: integrin- $\alpha 5$ (ITGA5), radixin (RDX), and RhoA (Supplemental Fig. 3). Hence, miR-31 induction did not elicit general cytostatic or cytotoxic responses.

Despite the lack of changes in their overall sizes, histological examination of the orthotopically arising 231 cell primary mammary tumors revealed stark differences following miR-31 activation. Consistent with prior observations (Valastyan et al. 2009b), 231 cells lacking miR-31 yielded primary tumors that displayed extensive histopathological evidence $a^{f}$ oc tromal invasion (Fig. 1C,D). In contrast, primary mors for hed by cells that expressed miR-31 for the extire Juration of the experiment had a well-encapsula d appe. ance hd were largely noninvasive (Fig. 1C s).

Interes ng month the ex erime $t$ in order to allow the formation of $\mathrm{i}$ as $\mathrm{e}$, poo capsulated primary mammary tumors, and was then activated for the remainder of the wan, the h tological appearance of these primary tumors was converte from an invasive phenotype to one that was largely honinvasive (Fig. 1C,D). Similarly, reversal of the invasiy ness of 231 cell primary tumors was observed 1. miR-31 was acutely expressed in even more advanced primary lesions beginning at $6 \mathrm{wk}$ post-implantacion (Fig. 1C,D). In contrast, however, no significant change in primary tumor histology occurred when miR31 was expressed for only the final $7 \mathrm{~d}$ of the experiment (Fig. 1C,D). These changes in invasiveness arose in the absence of alterations in the differentiation state of these primary tumors (Supplemental Fig. 4). Together, these observations revealed that activation of miR-31 in established primary mammary tumors was capable of reversing their already-acquired invasiveness.

We also examined these various tumor-bearing mice in order to determine the effects of acute miR-31 expression on metastasis formation in the lungs. As anticipated (Valastyan et al. 2009b), in the absence of miR-31 expression, 231 cells generated large numbers of pulmonary metastases within 2 mo of implantation (Fig. 1E,F). Moreover, lung metastasis was strongly impaired when miR-31 was expressed for the entire duration of the assay (Fig. 1E,F). Notably, if miR-31 was not expressed for the first month of the experiment - thereby permitting the establishment of micrometastases in the lungs-but was then activated for the remainder of the study, a substantial reduction in the number of pulmonary metastases was observed (Fig. 1E,F). In contrast, expression of miR-31 only during the final $2 \mathrm{wk}$ or final $1 \mathrm{wk}$ of the experiment did not significantly reduce metastatic burden in the lungs (Fig. 1E,F).

We reasoned that failure of miR-31 activation to diminish the incidence of pulmonary metastases at late time points in this assay could be attributable to either (1) a fundamental inability of acutely expressed miR-31 to alter the behavior of advanced and robustly growing 
A

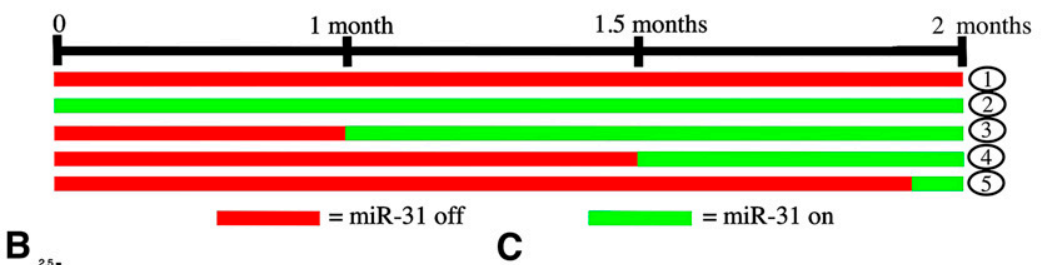

B $_{25} \quad$ C

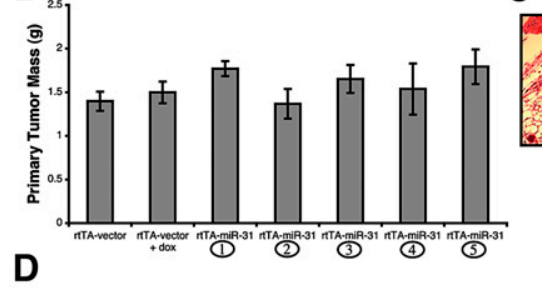

D

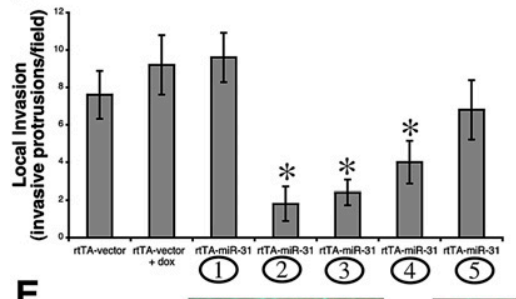

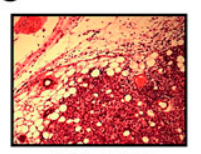

rtTA-vector

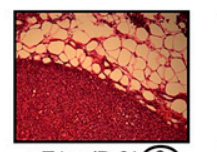

rtTA-miR-31 (2)

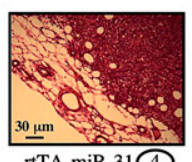

rtTA-miR-31 (4)
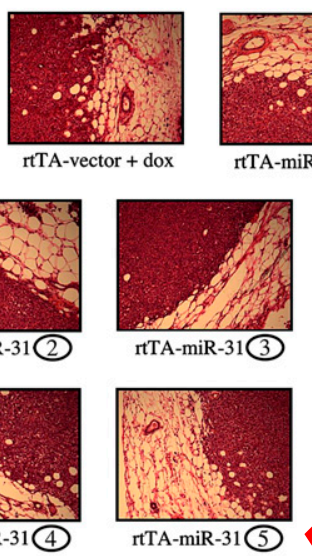

Figure 1. Acute miR-31 expression drives regression of established spontaneous lung metastases. (A) Overview of the dox-controlled intervention strategy for acute miR-31 expression upon orthotopic implantation of the indicated GFP-labeled 231 cells. (B) Masses of 231 cell primary mammary tumors $56 \mathrm{~d}$ after orthotopic injection. $n=5 .(C)$ Hematoxylin and eosin $(\mathrm{H} \& \mathrm{E})$ staining of primary mammary tumors $56 \mathrm{~d}$ subsequent to orthotopic implantation. (D) Quantification of primary mammary tumor local invasion $56 \mathrm{~d}$ following orthotopic injection. $n=5$. (Asterisks) $P<0.04$ relative to reverse tetracyclinecontrolled tr tivator (rtTA)-miR-31 cells (no dox t atmen $(E)$ Fluorescent images of murin lungs to isualize disseminated 231 lls d afte orthotopic implantat. 1. (F) Qu. tific on of lung metastatic urden $6 \mathrm{~d}$ a orthotopic injection. $n=$ (A erisks) $P<0.04$ relative to rtTA-miR31 ells (n dox treatment). All error bars repr ep mean \pm SEM.
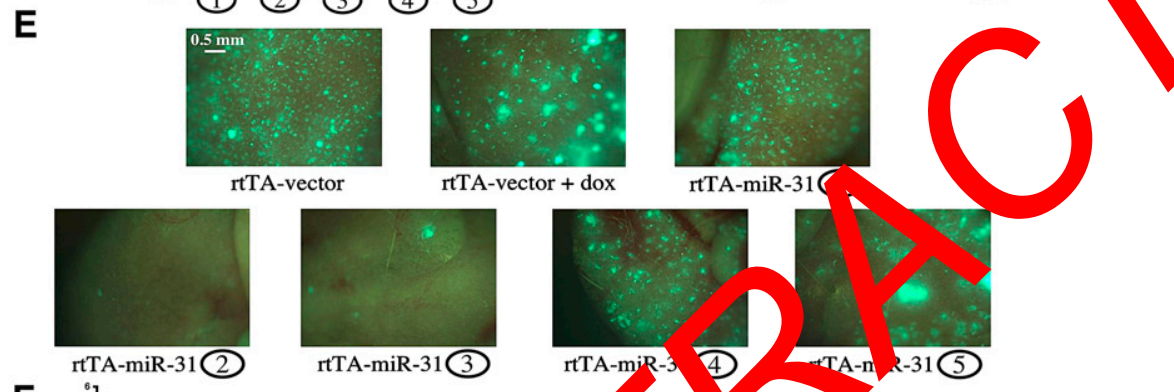

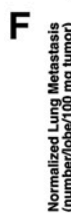

rtTA-miR-31

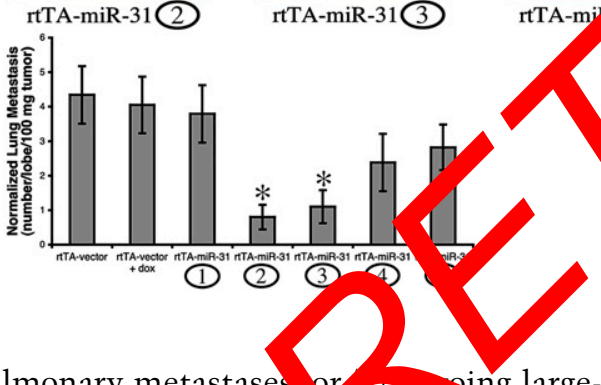

pulmonary metastases or and large-scale tumor cell seeding of the lu s from the already-massive, orthotopically implanted primary mammary tumors present in these mice; such seeding may have masked the potential effects of miR-31 induction on alreadyestablished metastases.

To distinguish between these two possibilities, the doxinducible 231 cells were again orthotopically implanted into mice; however, we now surgically resected the primary mammary tumors 1 mo after implantation-a time point selected in order to ensure that initial dissemination of carcinoma cells to the lungs had already occurred. miR31 expression was then induced at time points identical to those used in the preceding study, and pulmonary metastasis was again evaluated 2 mo post-injection (Fig. 2A); in addition, the overall survival of these animals was investigated. Notably, the final three induction time points in this assay occurred subsequent to resection of the primary tumors. Thus, in addition to allowing us to

distinguish between the two alternative models proposed above, this intervention strategy more faithfully recapitulated the situation encountered in clinically arising carcinomas, where a patient's primary tumor is almost always surgically resected prior to initiating therapies designed to treat systemic metastatic disease (Steeg 2006).

Consistent with earlier observations, acute miR-31 expression did not affect 231 cell primary mammary tumor growth (Fig. 2B). Also anticipated were our observations that the number of pulmonary metastases was strongly impaired when miR-31 was either expressed for the entire course of the study or activated immediately following primary tumor resection at 1 mo post-injection (Fig. $2 \mathrm{C}, \mathrm{D}$ ). Importantly, anti-metastatic influences stemming from acute miR-31 expression were also observed when induction of this miRNA occurred only at later time points in the assay: Activation of miR-31 for either the final $2 \mathrm{wk}$ or final 1 wk of the study sufficed to reduce metastatic burden in the lungs (Fig. 2C,D). 
A

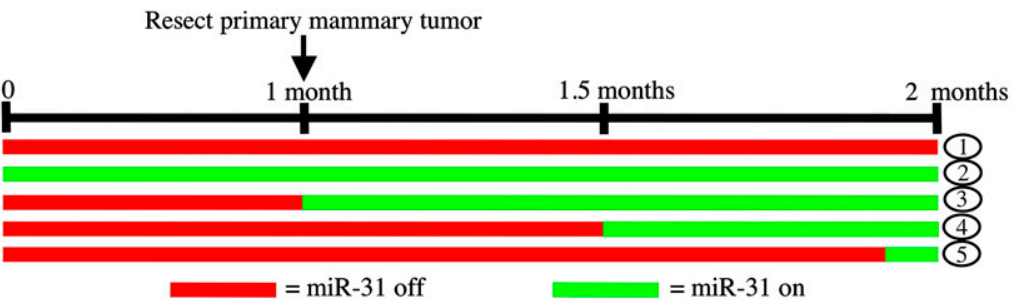

B

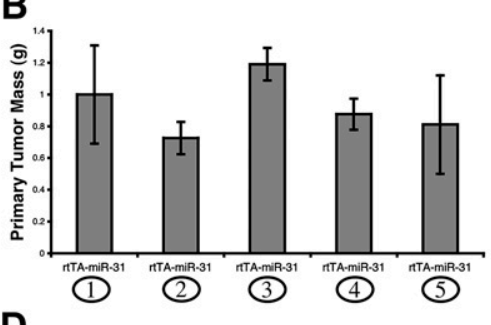

D

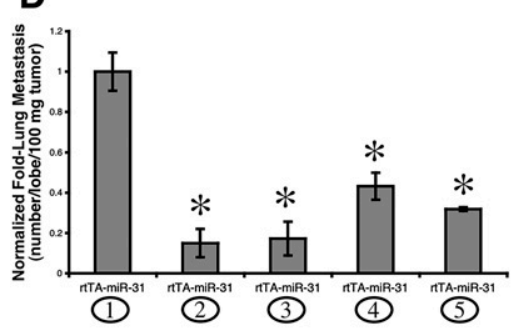

C

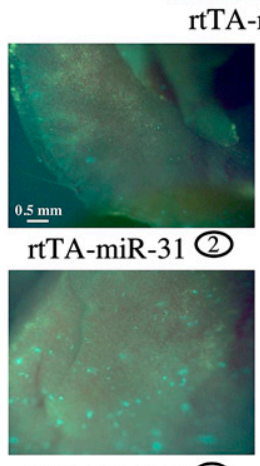

rtTA-miR-31 4

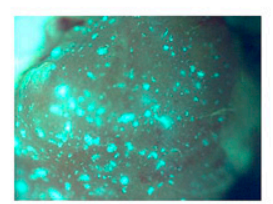

rtTA-miR-31 (1)

Figure 2. Acute miR-31 expression after primary mammary tumor resection triggers regression of established spontaneous pulmonary metastases. (A) Schematic depicting the dox-controlled intervention strategy for acute miR-31 expression upon orthotopic implantation of the indicated GFP-labeled 231 cells. Primary mammary tumors were surgically resected $26 \mathrm{~d}$ after injection. $(B)$ Masses of resected 231 cell primary mammary tumors $26 \mathrm{~d}$ subsequent to orthotopic implantation. $n=4$. $(C)$ Fluorescent images of murine lungs to visualize disseminated 231 cells $66 \mathrm{~d}$ after orthotopic injection. $(D)$ Quantification of metastatic burden in the ly $6 \mathrm{~d}$ after orthotopic implantatior $n=4$. (sterisks) $P<0.004$ relative to TA-miR- cells (no dox treatment). (E) $\mathrm{K}$ lan-Me r curves depicting survival in thi sssay $n=5$. (Asterisks) $P<0.05$ $r$ ative $T$ A-miR-31 cells (no dox treatment); $P$-value is based on a log-rank test.

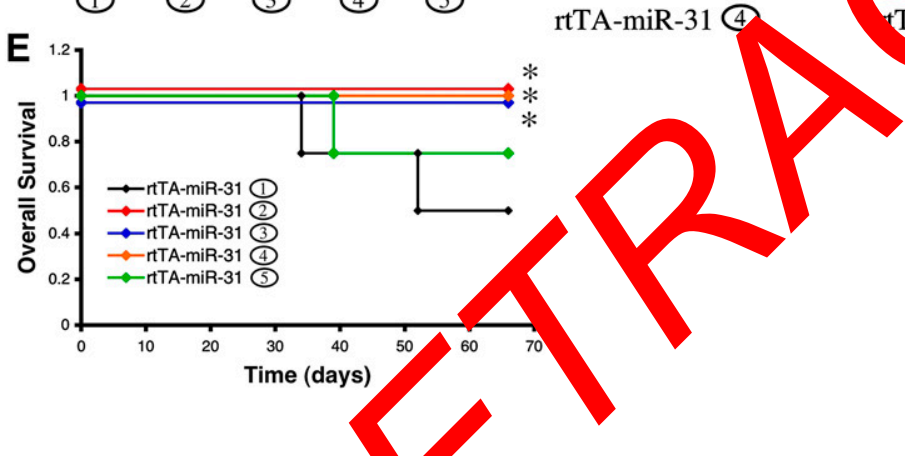

These observatic oth efo der nstrated that acutely expressed miR-2 was Indee apable of altering the behavior of robus $v$ arready-established pulmonary metastases. O1 ote, $\mathrm{miR}-31$ activation in these intervention assays suffic to prolong the survival of these animals (Fig. 2E). Assessed collectively, these experiments indicated that induction of miR-31 expression in both primary mammary tumors and established lung metastases was capable of evoking anti-metastatic therapeutic benefits.

\section{miR-31 activation triggers regression of established experimental lung metastases}

The orthotopic implantation protocol used above allowed us to gauge the effects of miR-31 activation on all steps of the invasion-metastasis cascade, including influences on the behavior of carcinoma cells present at their primary site of growth. However, we wished to further investigate the consequences of acutely expressing miR-31 exclusively in already-seeded metastases. To do so, we introduced the dox-inducible 231 cells into mice intravenously via the tail vein, a protocol that ensures that large numbers of cells are rapidly trapped in the lung microvasculature. In this setting, we activated miR-31 either (1) at no point during the study, (2) for the entire duration of the 3-mo experiment, (3) only after small pulmonary micrometastases had formed at 1 mo following implantation, (4) subsequent to the establishment of moderately sized macroscopic metastases in the lungs at 2 mo after injection, or (5) only after large macroscopic pulmonary metastases had developed at 11 wk post-implantation (Fig. 3A). We then assayed the effects of miR-31 induction on metastatic burden and overall survival.

Consistent with prior findings (Valastyan et al. 2009b), in the absence of miR-31 expression, 231 cells formed numerous macroscopic lung metastases within 3 mo of injection (Fig. 3B-D). Also, continuous miR-31 expression during the entire course of the experiment substantially impaired both the overall number of pulmonary metastases and their metastatic colonization efficiency (Fig. 3B-D). These differences in metastatic potential were not attributable to 
A

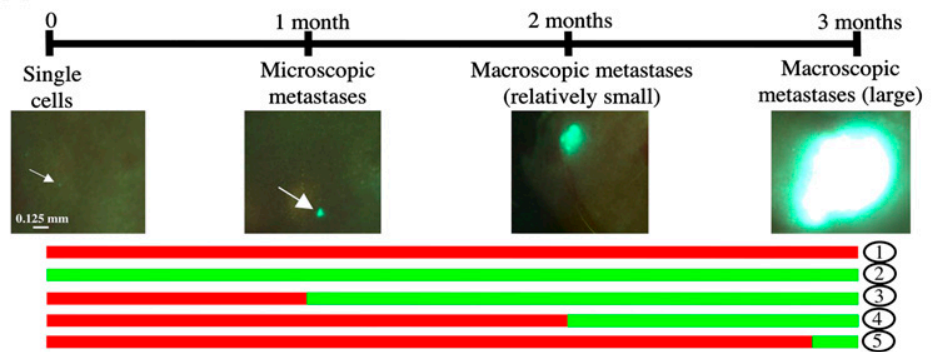

B

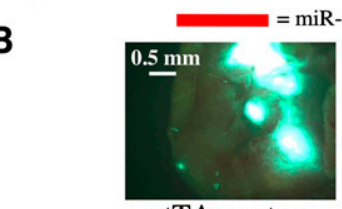

rtTA-vector

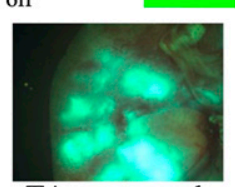

rtTA-vector + dox

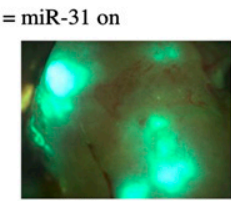

rtTA-miR-31

(1)

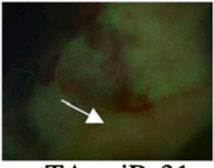

rtTA-miR-31

C
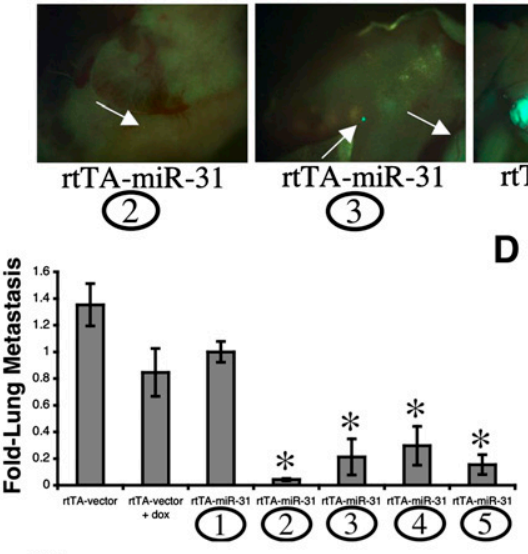

D
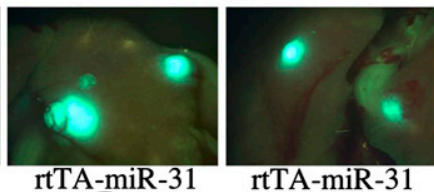

(4)
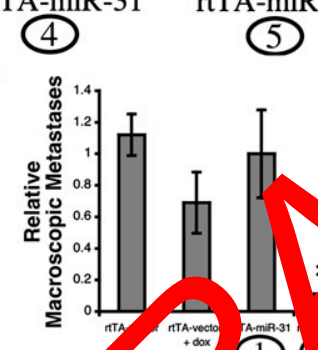

(5)

\section{(1)} C)

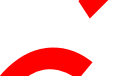

Figure 3. miR-31 activation drives regression of established experimental lung metastases. $(A)$ Overview of the dox-mediated intervention strategy for acute miR-31 expression upon intravenous injection of the indicated GFP-labeled 231 cells via the tail vein. Images document the normal progression of control 231 cells lacking miR-31 in the lungs in this assay. (Arrows) Micrometastases. (B) Fluorescent images of murine lungs to visualize 231 cells $88 \mathrm{~d}$ after intravenous implantation. (Arrows) Micrometastases. (C) Quantification of metastatic burden in the lungs $88 \mathrm{~d}$ following intravenous implantation. $n=5$. (Asterisks) $P<0.05$ rel to rtTA-miR-31 cells (no dox treat ent). A Quantification of the relative evalence $f$ macroscopic metastase in th lungs $\& \mathrm{~d}$ subsequent to into venous in ctio $n=5$. (Asterisks) $P<$ $05 \mathrm{re}^{\prime}$ cive $1 \mathrm{~A}-\mathrm{miR}-31$ cells (no dox a ant). (E) Kaplan-Meier curves depictin urviv? $n$ this assay. $n=15$. (Asterisks) $P<05$ elative to rtTA-miR-31 cells (no dox t ratment); $P$-value is based on a logrank test. All error bars represent mean \pm EM.

$\mathbf{E}$

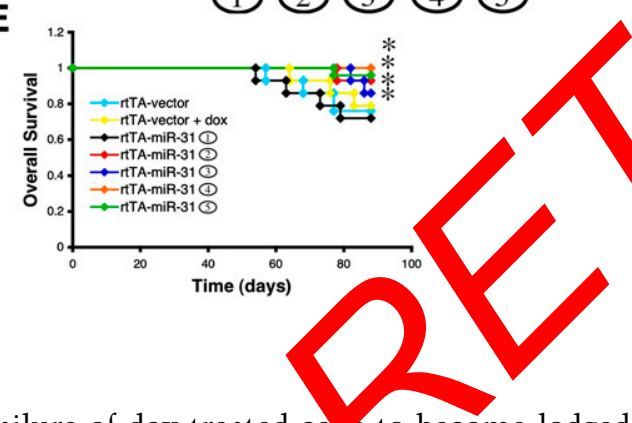

failure of dox-treated ce to become lodged initially in the lung microvasculature Supplemental Fig. 5).

Notably, if miR-31 was no expressed for the first month after injection in order to permit the formation of small pulmonary micrometastases by 231 cells, but was then induced for the following 2 mo of the experiment, strong anti-metastatic responses were still evoked (Fig. 3B-D). We also evaluated the consequences of activating miR-31 only in already-robustly growing macroscopic lung metastases. Remarkably, even when miR-31 was only expressed during the final $7 \mathrm{~d}$ of the experiment, significant reductions were observed in both the total number of pulmonary metastatic foci and the relative prevalence of macroscopic lung metastases (Fig. 3B-D). Of interest, miR-31 induction in these assays prolonged the survival of these animals (Fig. 3E). Hence, these data provided further evidence that activation of miR-31 specifically in established lung metastases elicited potent anti-metastatic therapeutic benefits.
We determined whether the responses evoked by miR31 induction occurred only within metastases seeded to the lungs or, instead, also operated in metastatic lesions established at other sites of dissemination. Accordingly, we performed intracardiac injections on mice using the dox-inducible 231 cells, a protocol that allows injected cells to bypass initial trapping in the lung microvasculature and thus seed a variety of sites throughout the body. We then expressed miR-31 at various time points after injection (Supplemental Fig. 6A). Interestingly, whereas miR-31 failed to impact the formation and colonization efficiency of liver metastases, activation of this miRNA in established bone metastases both diminished the overall number of metastatic foci and prevented the outgrowth of residual lesions into large macroscopic metastases (Supplemental Fig. 6B-E). In these assays, miR-31 expression prolonged the survival of these animals (Supplemental Fig. 6F). Hence, the anti-metastatic responses 
triggered by miR-31 induction did not arise solely in metastatic foci seeded to the lungs.

\section{Activation of miR-31 in established pulmonary metastases triggers metastasis-specific cell cycle arrest and apoptosis}

We undertook to determine the cellular mechanisms underlying the profound anti-metastatic effects elicited by miR31 induction. To do so, we performed immunohistochemical staining on tissue sections from animals bearing the dox-inducible 231 cells, surveying the expression of markers of neo-vascularization, cell cycle progression, and apoptosis.

miR-31 activation failed to impact vascular density within both primary mammary tumors and pulmonary metastases (Supplemental Fig. 7). However, regardless of the time point at which miR-31 was induced, increasing this miRNA's levels diminished the proportion of disseminated tumor cells in the lungs that were actively dividing (Fig. 4A,B; Supplemental Fig. 8A). Moreover, an increased frequency of apoptotic cells was observed following miR-31 induction in already-macroscopic pulmonary metastases (Fig. 4C,D; Supplemental Fig. 8B). These effects of miR-31 activation on cell cycle progression and apoptosis occurred to equivalent extents in large macroscopic pulmonary metastases and relatively smaller macroscopic metastatic lesions (Supplemental Fig. 9). Importantly, the observed anti-proliferative and proapoptotic responses in lung metastases were not attributable to general cytostatic or cytotoxic influences, since activation of miR-31 in 231 cell primary mammary tumors failed to impair cell cycle progression or promote apoptosis (Fig. 4E,F). Hence, miR-31 was capable of using at least two distinct cellular mechanisms-induction of both cytostasis and apoptosis - to antagonize the metastatic outgrowth of already-disseminated tumor cells.

We proceeded to determine the relative temporal order of the molecular and phenotypic responses triggered by miR-31 activation-spe Alca $v$, induction of (1) cytostasis, (2) apoptosis, and (2 pulmon ry metastatic regression. Accordingly, we i-tra nously njected the dox-inducible 231 cells via th tail ve alle red them to form macroscopic pulm 1ary $\mathrm{w}$ tast. over a period of $12 \mathrm{wk}$, and then exprsso $r-31$ in these established macroscopic metast es for ther $(1, \mathrm{~d},(2) 1 \mathrm{~d},(3) 2 \mathrm{~d}$, or (4) $7 \mathrm{~d}$.

$\mathrm{O} \sim \mathrm{y}$ after $\mathrm{n}$ action, miR-31 increased the incidence of poptoti tumor cells in the lungs; however,

\section{C}
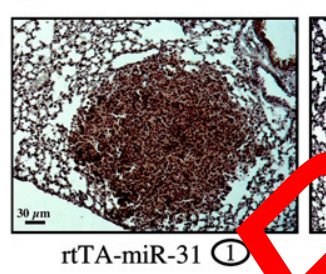

\section{E}

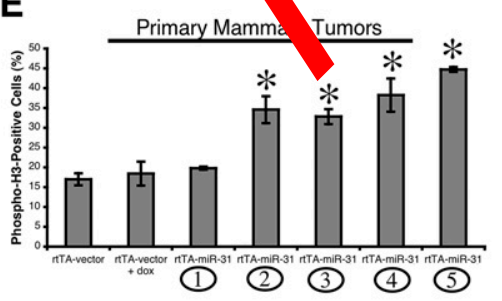

G

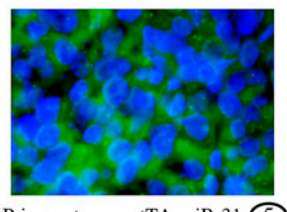

Primary tumor, rtTA-miR-31 (5)

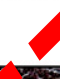

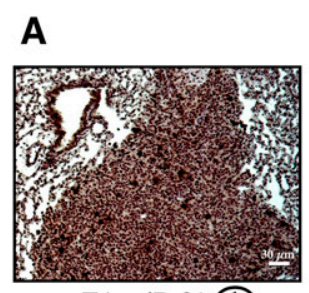

rtTA-miR-31 (1)

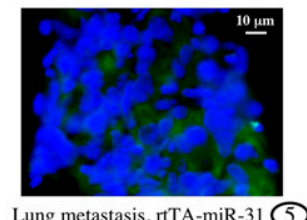

Lung metastasis, rtTA-miR-31 (5)

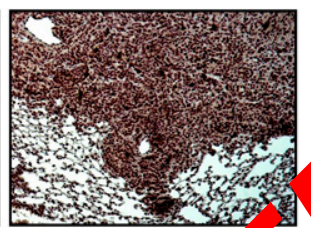
rtTA-miR-31 $C$

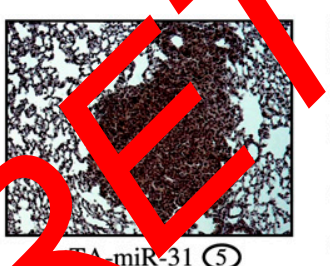

F

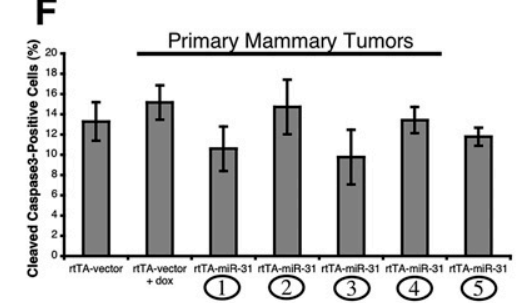

H

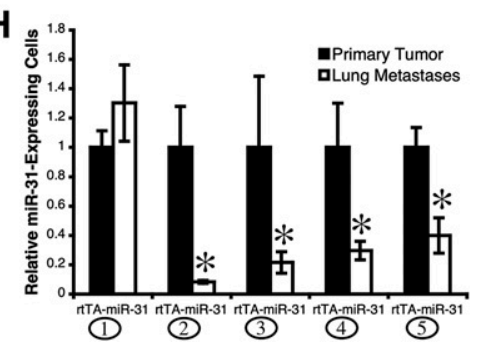

Figure 4. Activation of miR-31 in established pulmonary metastases triggers metastasis-specific cell cycle arrest and apoptosis. (A) 231 cell lung metastases 88 $\mathrm{d}$ after intravenous injection via the tail vein, immunohistochemically stained for phosphorylated histone H3 (phospho-H3). (B) Quantification of phospho-H3 staining in pulmonary metastases $88 \mathrm{~d}$ post-intravenous implantation. $n=5$. (Asterisks) $P<$ 0.03 relative to rtTA-miR-31 cells (no dox treatment). (C) 231 cell lung metastases $88 \mathrm{~d}$ after intravenous introduction, immunohistochemically stained for cleaved caspase3. (D) Quantification of cleaved caspase 3 staining in pulmonary metastases $88 \mathrm{~d}$ following intravenous injection. $n=5$. (Asterisks) $P<0.03$ relative to rtTA-miR-31 cells (no dox treatment). (E) Quantification of phospho-H3 staining in 231 cell primary mammary tumors $56 \mathrm{~d}$ post-orthotopic injection. $n=5$. (Asterisks) $P<0.03$ relative to rtTA-miR-31 cells (no dox treatment). (F) Quantification of cleaved caspase3 staining in 231 cell primary mammary tumors $56 \mathrm{~d}$ subsequent to orthotopic implantation. $n=5$. $(G)$ In situ hybridizations for miR-31 (green) in animal-matched 231 cell primary mammary tumors and lung metastases $56 \mathrm{~d}$ following orthotopic implantation. (Blue) DAPI counterstain. $(H)$ Quantification of miR-31 staining in animal-matched primary mammary tumors and lung metastases $56 \mathrm{~d}$ post-orthotopic injection. $n=5$. (Asterisks) $P<0.03$ relative to rtTA-miR-31 cells (no dox treatment). All error bars represent mean \pm SEM. 
neither cytostasis nor a significant reduction in metastatic burden in the lungs was observed (Supplemental Fig. 10A-E). By 2 d following dox treatment, miR-31 activation not only enhanced apoptosis, but also diminished both the overall number of pulmonary metastatic foci and the relative prevalence of macroscopic metastases; at this time point, cytostatic influences were still not observed (Supplemental Fig. 10A-E). Finally, as anticipated, after $7 \mathrm{~d}$ of miR-31 expression, metastatic regression was once again observed, but was now accompanied by both apoptotic responses and cell cycle arrest in pulmonary metastatic lesions (Supplemental Fig. 10A-E). miR-31 activation failed to impact vascular density at any of the assayed time points (Supplemental Fig. 10F). Thus, miR31-imposed metastatic regression was preceded by an elevated frequency of apoptotic cells in already-seeded pulmonary lesions, providing a mechanistic rationale for their observed diminution. In contrast, miR-31-dependent cytostasis occurred only at time points subsequent to the initial induction of metastatic regression in the lungs.

In light of the above-cited data, we posited that the few residual pulmonary metastases that persisted following dox administration might have succeeded in doing so by failing to appropriately up-regulate miR-31 expression in response to dox. We therefore performed in situ hybridizations against miR-31 to determine whether these residual metastatic cells still expressed miR-31 appropriately in response to dox. Indeed, the residual 231 cells that continued to grow in the lungs of mice exposed to dox for prolonged intervals were greatly impaired in their ${ }^{1} \cdot 1$ ty to properly induce miR-31 (Supplemental Fig. 1).Mo over, when the proportion of miR-31-expressin cells as compared between residual pulmonary met case of a the corresponding animal-matched primary $p$ nmary mors subsequent to dox treatment, we found hat a wer percentage of cells in the lung met cases ex 31 (Fig. 4G,H).

We wondered whether the g, wth avantage conferred by miR-31 loss in pulmonarv mo ases oxurred specifically within the conte of his vi microenvironment. To investigat this $y$ ssibi , we assayed the effects of miR-31 activa ior cells that were isolated from the lungs of mice Tinn et al. 2005). Induction of miR-31 in these cells ex vo failed to trigger cytotoxic responses (Supplemental Fig.12). Moreover, cells obtained from lung metastases did not display augmented sensitivity in vitro to miR-31 activation-dependent modulation of anoikis, invasiveness, or motility (Supplemental Fig. 12). Hence, the cytotoxic responses conferred by miR-31 induction depended on the residence of tumor cells within particular microenvironmental contexts.

\section{Restoration of endogenous miR-31 function in established lung metastases reduces metastatic burden}

It remained possible that metastatic regression evoked by miR-31 induction arose due to some peculiarity of either 231 cells or our expression vector strategy. To address these possibilities, we evaluated the consequences of acutely restoring endogenous miR-31 function in an independent breast cancer cell line. In these experiments, we used a dox-repressible modified miR-31 miRNA sponge vector system. miRNA sponges act as competitive inhibitors of miRNA activity by sequestering miRNAs of interest, thereby diverting them from their endogenous mRNA targets (Ebert et al. 2007; Valastyan et al. 2009b).

The dox-repressible miR-31 sponge vector system was introduced into otherwise nonmetastatic MCF7-Ras human breast cancer cells. These cells normally express miR31 , and constitutive miR-31 sponge expression confers metastatic competence on them (Valastyan et al. 2009b). miR-31 activity was impaired specifically in the absence of dox-mediated repression of the miR-31 sponge (Supplemental Fig. 13A). As anticip can alastyan et al. 2009b), this inhibition of endoger as miR- function enhanced various in vitro surrog te $\mathrm{i}$ rkers o metastatic capacity (invasion, motility, a anoik resis ance) without affecting cell proliferati (Sup lem, Fig. 13B-E).

When these lox ep ssible miR-31 sponge-expressing MCF7-Ras o is wer njecte intravenously into mice via the tail $\mathrm{V} \Lambda$, activat $\mathrm{v}$ endogenous miR-31 function in already-seed pulmonary micrometastases reduced the tota a mer of is tastatic foci in the lungs and prevented th outgrowth of residual pulmonary lesions into large $\mathrm{m}$ croscopic metastases (Supplemental Fig. 14A-D). These an metast ic influences were accompanied by prolonged survi these animals (Supplemental Fig. 14E). Morerr, restoration of endogenous miR-31 activity in estabsho lung metastases induced both cell cycle arrest and apoptosis (Supplemental Fig. 14F,G). These effects were not attributable to differing abilities of these cells to lodge initially in the lung microvasculature (Supplemental Fig. 15). Robust dox-dependent repression of the sponge persisted for the entire duration of the assay (Supplemental Fig. 16). Hence, the anti-metastatic responses observed upon acute induction of miR-31 in already-seeded metastases did not arise solely in 231 cells, nor were these effects confined to experiments in which miR-31 was ectopically expressed.

\section{Suppression of ITGA5, RDX, and RhoA can mediate miR-31-evoked regression of established pulmonary metastases}

We sought to identify downstream effectors of miR-31 whose suppression by this miRNA might account for its anti-metastatic influences when acutely expressed. In prior work, we discovered that ITGA5, RDX, and RhoA are direct downstream targets of miR-31 whose concomitant restored expression sufficed to override the ability of constitutively expressed miR-31 to inhibit lung metastasis (Valastyan et al. 2009a,b). In further support of the key roles of these effectors, we found that concurrent shRNA-conferred suppression of ITGA5, RDX, and RhoA closely phenocopied the anti-metastatic influences of constitutively expressed miR-31 (Valastyan et al. 2010). Guided by these studies, we assessed the ability of re-expressing ITGA5, RDX, and/or RhoA to alter the effects of miR-31 activation.

To this end, we created the 16 potential combinations of 231 cells expressing ITGA5, RDX, RhoA, dox-inducible 
miR-31, and/or the corresponding control vectors (Supplemental Fig. 17A,B). In these experiments, the ITGA5, RDX, and RhoA constructs were rendered miRNA-resistant via deletion of their respective 3' untranslated regions. miR-31, ITGA5, RDX, and RhoA did not affect cell proliferation in vitro, ruling out nonspecific cytostatic or cytotoxic effects (Supplemental Fig. 17C). As anticipated (Valastyan et al. 2009a), individual re-expression of ITGA5, RDX, or RhoA reversed, at least partially, in vitro defects in invasion, motility, and anoikis resistance conferred by miR-31 induction; the extent of reversal was more pronounced when these effectors were re-expressed in pairwise combinations, and concomitant restored expression of ITGA5, RDX, and RhoA completely abrogated miR-31's effects on these phenotypes (Supplemental Fig. 17D-F). ITGA5, RDX, and RhoA did not enhance these traits in 231 cells lacking miR-31 (Supplemental Fig. 17D-F). Hence, re-expression of ITGA5, RDX, and RhoA could reverse the influences of miR-31 induction on in vitro surrogates of metastatic potential.
We wished to determine whether re-expression of ITGA5, RDX, and/or RhoA was also able to block effects stemming from activation of miR-31 in established pulmonary metastases and primary tumors. To do so, we orthotopically implanted the dox-inducible 231 cells reexpressing the various combinations of these effectors in the mammary fat pads of mice. miR-31 was then induced either (1) at no point during the 2-mo experiment or (2) only after lung micrometastases had formed at 1 mo postimplantation. The consequences of miR-31 activation on primary tumor development and pulmonary metastasis were then evaluated.

miR-31, ITGA5, RDX, and RhoA did not affect 231 cell primary mammary tumor growth (Fig. 5A). This lack of an effect on primary ty $10 \mathrm{r}$ ze could not be ascribed to failure of dox-mediz up-re llation of miR-31 in the implanted cells or lo of the ability to continuously re-express ITC 5 , RD an or RhoA (Supplemental Fig. 18).
A

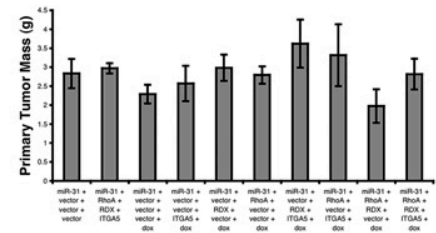

C
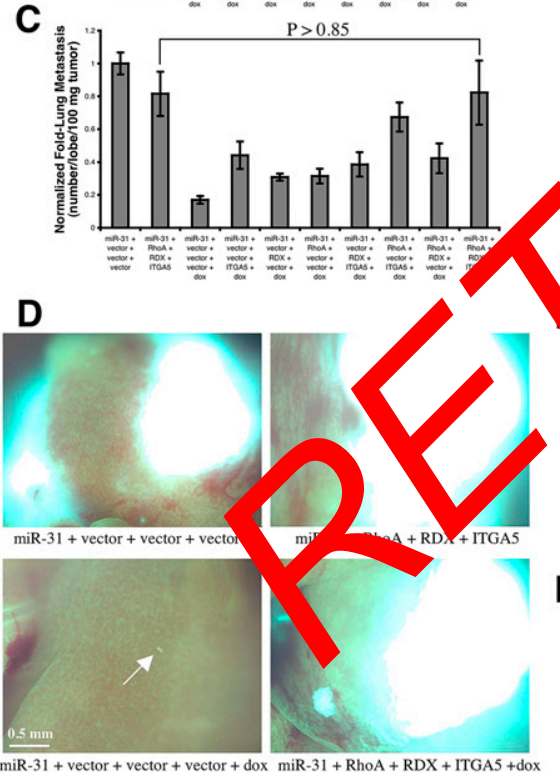

miR-31 + vector + vector + vector + dox miR-31 + RhoA + RDX + ITGA5 +dox

G

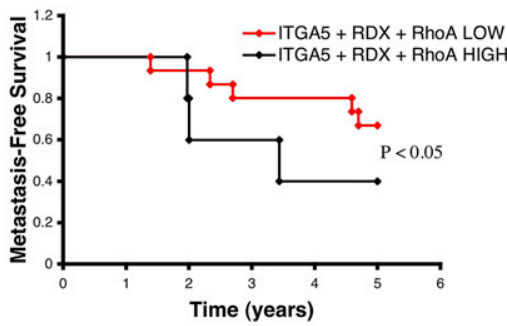

B
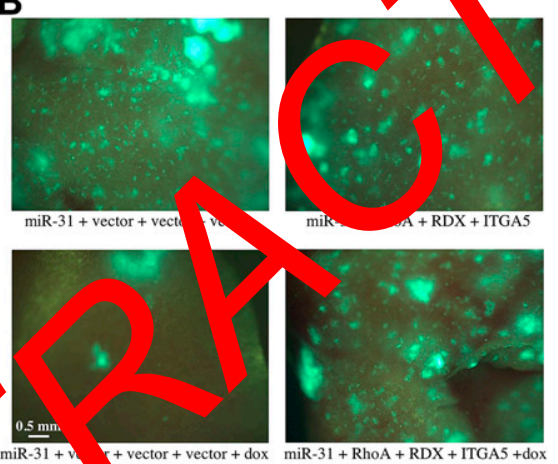

+ vector + vector + dox miR-31 + RhoA + RDX + ITGA5 +dox
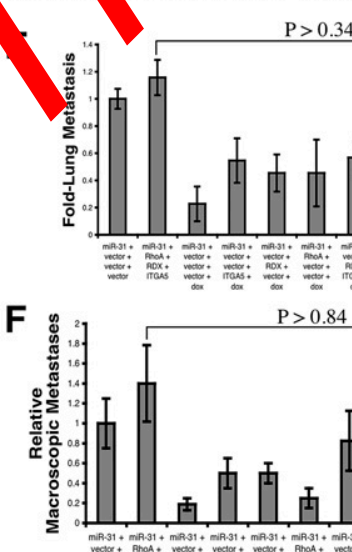

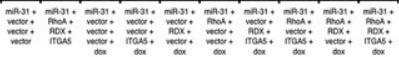

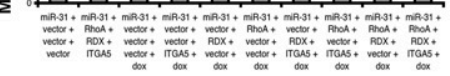

H

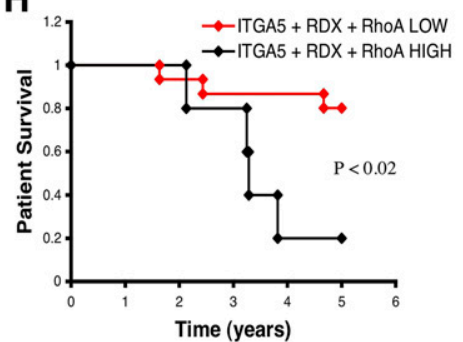

are 5. Suppression of ITGA5, RDX, and RhoA can mediate miR-31-evoked regression of established pulmonary metastases. (A) Masses of 231 cell primary mammary tumors $54 \mathrm{~d}$ subsequent to orthotopic injection of the indicated GFP-labeled 231 cells. $n=4$. (miR-31) rtTA-miR-31. $(B)$ Fluorescent images of murine lungs to visualize disseminated 231 cells $54 \mathrm{~d}$ after orthotopic implantation. $(C)$ Quantification of metastatic burden in the lungs $54 \mathrm{~d}$ after orthotopic injection. $n=4$. (D) Fluorescent images of murine lungs to visualize 231 cells $92 \mathrm{~d}$ after intravenous implantation via the tail vein. (Arrows) Micrometastases. (E) Quantification of metastatic burden in the lungs $92 \mathrm{~d}$ following intravenous implantation. $n=5 .(F)$ Quantification of the relative prevalence of macroscopic metastases in the lungs $92 \mathrm{~d}$ subsequent to intravenous injection. $n=5$. (G) Kaplan-Meier curves for 295 human primary breast tumors depicting 5-yr metastasis-free survival, stratified based on coordinate differential expression of ITGA5, RDX, and RhoA; $P$-value based on a log-rank test. $(H)$ KaplanMeier 5-yr survival curves for 295 breast cancer patients, stratified based on coordinate differential expression of ITGA5, RDX, and RhoA; $P$-value is based on a log-rank test. All error bars represent mean \pm SEM. 
We also investigated whether restoring ITGA5, RDX, and/or RhoA levels would prevent acutely expressed miR-31 from causing metastatic regression in the lungs. Of interest, individually re-expressing either ITGA5, RDX, or RhoA in 231 cells partially reversed the capacity of miR-31 activation to reduce pulmonary metastatic burden (Fig. 5B,C). Simultaneous pairwise re-expression of any two of these miR-31 effectors resulted in only moderately additive effects in blocking miR-31-evoked metastatic regression (Fig. 5B,C). However, concomitant re-expression of ITGA5, RDX, and RhoA completely abrogated the anti-metastatic influences of miR-31 induction in the lungs (Fig. 5B,C). In contrast, ITGA5, RDX, and RhoA did not increase pulmonary metastasis in 231 cells lacking miR-31 (Fig. 5B-C), consistent with prior work (Valastyan et al. 2009a). Hence, ITGA5, RDX, and RhoA were functionally important downstream mediators of miR-31-imposed pulmonary metastatic regression.

We also wished to evaluate the influences of ITGA5, RDX, and/or RhoA on metastatic regression conferred by miR-31 induction in assays where these targets were re-expressed exclusively in already-established lung metastases. We therefore intravenously injected the doxinducible 231 cells re-expressing the various combinations of these miR-31 downstream effectors into mice. miR-31 was then induced either (1) at no point during the 3 -mo experiment or (2) only after macroscopic pulmonary metastases had formed at 2 mo post-injection. The consequences of miR-31 activation on lung metastasic ere then assessed.

We discovered that individual re-expression of eit er ITGA5, RDX, or RhoA partially blocked $t^{2} \mathrm{ca}$ ca miR-31 activation to diminish the nur er of 21 cell pulmonary metastases (Fig. 5D,E). Sin Mar) pairwi reexpression of any two of these $t^{1}$ ce miR 1 effectors resulted in partial reversal of the cects of acuto induced miR-31 on lung metastases (F, 5D . Notably, concurrent restoration of ITGA5, RDX, "RhoA levels entirely prevented miR-31 activa on $\mathrm{m}$ duci o the number of metastatic foci in th lungs, Fig. 5 . As anticipated (Valastyan et al. 2009a, IT enhance pulmonary met tasis in 231 cells lacking miR31 (Fig. 5D,E).

In addition to the observed impact on the number of pulmonary metastases formed by 231 cells in this assay, we also evaluated the effects of ITGA5, RDX, and/or RhoA re-expression on lung metastatic colonization efficiency following miR-31 activation. Interestingly, individual re-expression of either ITGA5 or RDX, but not RhoA, increased the prevalence of macroscopic lung metastases upon miR-31 induction (Fig. 5F). Moreover, while concomitant re-expression of ITGA5, RDX, and RhoA failed to enhance pulmonary metastatic colonization efficiency in 231 cells lacking miR-31, simultaneously restoring levels of ITGA5 and RDX sufficed to entirely override the capacity of miR-31 induction to diminish the prevalence of macroscopic lung metastases (Fig. 5F). Collectively, the preceding studies revealed that the regression of already-established pulmonary metastases elicited by
miR-31 could be attributed, in significant part, to this miRNA's capacity to regulate ITGA5, RDX, and RhoA.

Based on these findings, we ascertained whether concomitant differential expression of ITGA5, RDX, and RhoA was associated with disease progression in clinical breast carcinomas. To do so, we examined microarray data from 295 primary human breast tumors (van de Vijver et al. 2002). Within this cohort, coordinate high-level expression of ITGA5, RDX, and RhoA was correlated with an increased propensity to develop metastases, as well as poor overall patient survival, relative to tumors containing low levels of these three proteins (Fig. 5G,H).

\section{ITGA5, RDX, and RhoA can $\longrightarrow$ rol metastasis-specific cell cycle arrest and apopt is evo ad by $m i R-31$ activation in established, ng meta ases}

To investigate the ce biologi bases nderlying the effects of ITGA5, RDX, and R oA pulmonary metastatic regression trigg rea by $\mathrm{AiR}-31$ induction, we used immunohistocher cal sta ing to camine neo-vascularization, cell cycle or ression, apoptosis in tissue sections derived from on otopically implanted animals bearing the vari an ox-indu ble 231 cells.

iiR-31, ITGA5, RDX, and RhoA did not alter vascular de sity wit in pulmonary metastases or primary mamma tumo (Supplemental Fig. 19). However, metastasis-sp cell cycle arrest evoked by miR-31 activation ld be partially circumvented by re-expressing either $\widehat{\Gamma G} 5$ or RhoA individually (Fig. 6A,B). Additionally, combined restoration of ITGA5 and RhoA levels rendered the proliferation of disseminated tumor cells in the lungs entirely insensitive to miR-31 induction (Fig. 6A,B). In contrast, RDX failed to reverse the cytostatic responses observed upon miR-31 activation in pulmonary metastases (Fig. 6A,B). ITGA5, RDX, and RhoA did not enhance cell cycle progression in primary mammary tumors; moreover, ITGA5, RDX, and RhoA failed to augment the proliferation of 231 cells lacking miR-31 in the lungs (Fig. 6A,B; Supplemental Fig. 20A). Hence, ITGA5 and RhoA were capable of interdicting metastasis-specific cell cycle arrest imposed by miR-31 activation.

231 cells re-expressing either ITGA5 or RDX were less sensitive to the metastasis-specific apoptosis otherwise triggered by miR-31 induction (Fig. 6C,D). Moreover, disseminated tumor cells in the lungs concomitantly reexpressing ITGA5 and RDX were completely refractory to the apoptotic responses elicited by miR-31 activation (Fig. 6C,D). In contrast, RhoA failed to impair miR-31's ability to trigger apoptosis in already-seeded pulmonary metastases (Fig. 6C,D). ITGA5, RDX, and RhoA did not alter the incidence of apoptotic cells in primary mammary tumors, nor did ITGA5, RDX, and RhoA affect apoptosis in lung metastases formed by 231 cells lacking miR-31 (Fig. 6C,D; Supplemental Fig. 20B). Therefore, ITGA5 and RDX were able to inhibit metastasis-specific apoptosis mediated by miR-31 induction.

Given these results, we reasoned that the previously observed selection against miR-31 expression in disseminated carcinoma cells should be attenuated upon concurrent 
A

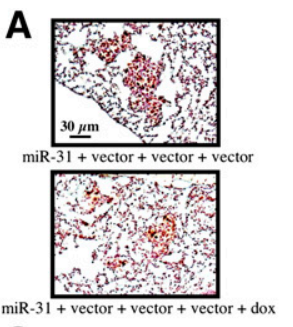

C
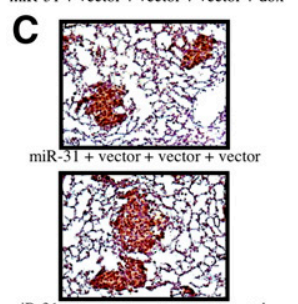

E

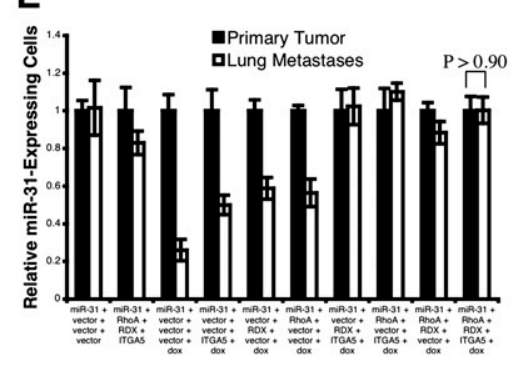

B
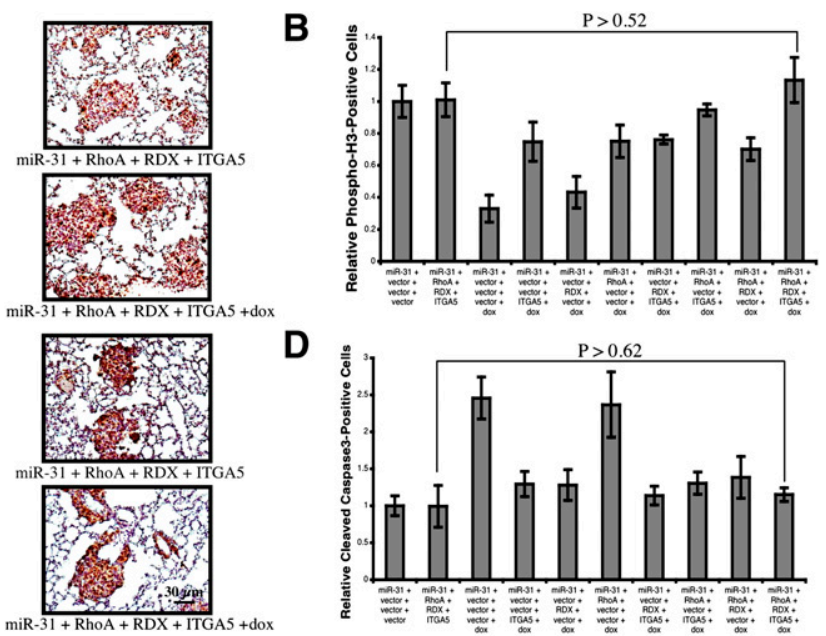

Figure 6. ITGA5, RDX, and RhoA can control metastasis-specific cell cycle arrest and apoptosis evoked by miR-31 activation in established lung metastases. (A) 231 cell lung metastases $54 \mathrm{~d}$ after orthotopic injection, immunohistochemically stained for phospho-H3. (miR-31) rtTA-miR-31. (B) Quantification of phospho-H3 staining in pulmonary metastases $54 \mathrm{~d}$ subsequent to orthotopic implantation. $n=5$. (C) 231 cell lung metastases $54 \mathrm{~d}$ post-orthotopic introduction, immunohistochemically stained for cleaved caspase3. (D) Quantification of cleaved caspase 3 staining in pulmonary metastases $54 \mathrm{~d}$ following orthotopic injection. $n=5$ rantification of miR-31 staining, as hieved $y$ in situ hybridizations, in an al-match 1 primary mammary tumors and ng met tases $54 \mathrm{~d}$ after orthotopic inject $n \quad 5$. All error bars represent

re-expression of ITGA5, RDX, and RhoA. Ind in s hybridizations revealed that, in the abser of TGA RDX, and RhoA re-expression, the propor on of hiR-3 expressing cells was reduced in $r$ du. almony metastases that persisted followir dox tre ment, relative to the percentage of cells that e ressed $\mathrm{iR}-31$ in animal-matched primary ma mary to ors (Fig. 6E). In contrast, however, simultar ously restori ITGA5, RDX, and RhoA levels permitte the $\mathrm{c}$ tinued maintenance of miR-31 expression in these metartases at frequencies indistinguishable f $\mathrm{mo}$ ose bser $\mathrm{d}$ in the corresponding primary mar mary amors g. 6E). Hence, concomitant re-expressio of $\mathrm{RDX}$, and RhoA allowed ongoing miR-31 in uction to be tolerated within lung metastases.

The Akt and Bim pathways are altered by miR-31, ITGA5, RDX, and RhoA in a metastasis-specific manner in established pulmonary metastases

We undertook to identify signal transduction networks operating downstream from miR-31 whose differential activation between primary mammary tumors and lung metastases might contribute to the metastasis-specific effects of this miRNA. To this end, we used immunohistochemical staining to examine the status of several prominent proliferation and survival pathways in tissue sections prepared from animals orthotopically implanted with the dox-inducible 231 cells.

Acute miR-31 expression failed to affect nuclear factor$\kappa \mathrm{B}(\mathrm{NF}-\kappa \mathrm{B})$ function in both pulmonary metastases and primary mammary tumors (Supplemental Fig. 21). In contrast, activation of the Akt pathway was impaired in lung metastatic foci in response to miR-31 induction, but was maintained at normal levels in primary mammary tumors upon acute expression of this miRNA (Fig. 7A,B; Supplemental Fig. 22). These influences on Akt activation status did not reflect a more widely acting dampening of Ras-dependent signaling, as the functional output of two other major Ras effector pathways-involving the mitogenactivated protein kinase (MAPK) and Ral-guanine nucleotide exchange factor (RalGEF) - was insensitive to miR-31 induction (Supplemental Fig. 23). In addition to metastasisspecific inhibition of Akt-dependent signaling, miR-31 induction also resulted in enhanced protein levels of the proapoptotic molecule Bim in lung metastases but not primary mammary tumors (Fig. 7C,D; Supplemental Fig. 24). Therefore, Akt activation and Bim protein levels were altered in a metastasis-specific fashion in response to miR31 activation in pulmonary metastases.

None of the three Akt-encoding mRNAs is a computationally predicted direct target of miR-31 (Grimson et al. 2007). Indeed, levels of these three mRNAs were unaffected by miR-31 activation (Supplemental Fig. 25). Consequently, it appeared that miR-31's influences on one or several Akt kinases were due to its effects on upstream regulators of these enzymes. In light of these observations, we considered the possibility that the Akt and/or Bim pathways might lie downstream from certain known miR-31 target genes. In particular, we determined whether Akt and Bim resided downstream from miR-31dependent suppression of ITGA5, RDX, and/or RhoA. 
A
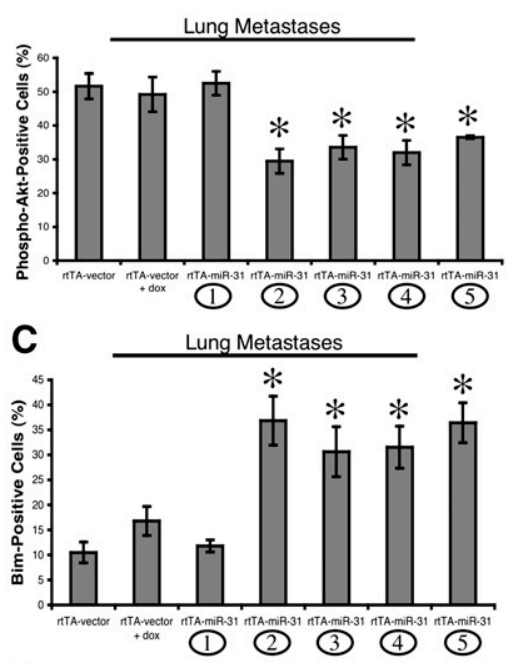

E

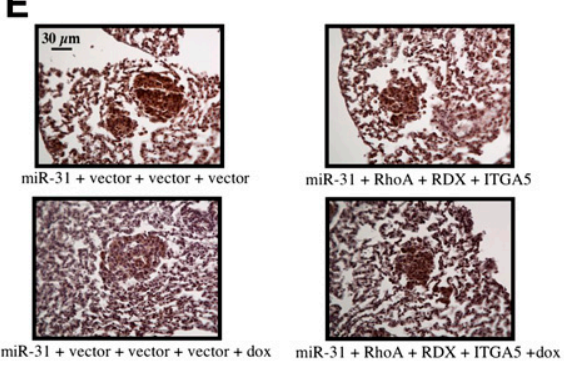

G
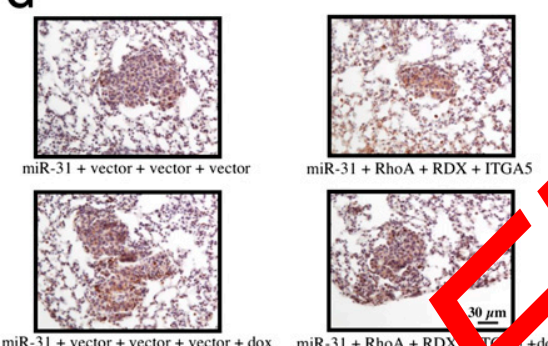

B

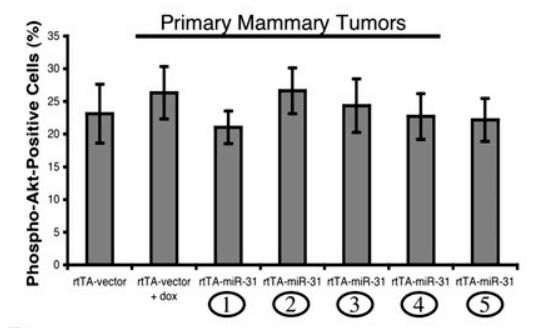

D

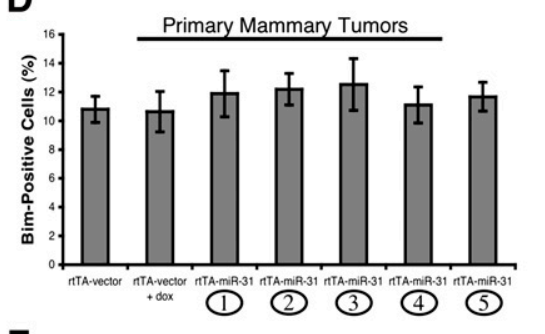

$\mathbf{F}$
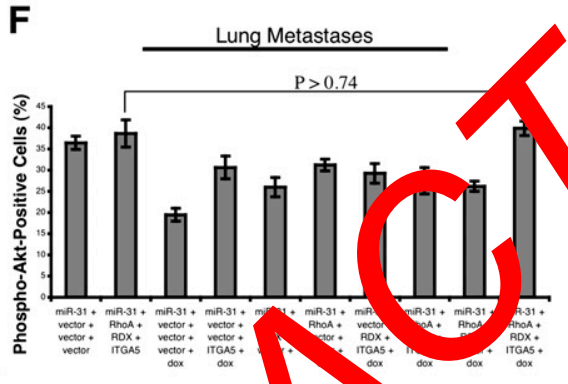

H

Figure 7. The Akt and Bim pathways are altered by miR-31, ITGA5, RDX, and RhoA in a metastasis-specific manner in established pulmonary metastases. (A) Quantification of phosphorylated Akt (phospho-Akt) staining in 231 cell pulmonary metastases $56 \mathrm{~d}$ following orthotopic implantation. $n=$ 5. (Asterisks) $P<0.02$ relative to rtTA-miR31 cells (no dox treatment). (B) Quantification of phospho-Akt staining in 231 cell primary mammary tumors $56 \mathrm{~d}$ post-orthotopic injection. $n=5 .(C)$ Quantification of Bim immunohistochemical staining in 231 cell pulmonary metastases $56 \mathrm{~d}$ following orthotopic implantation. $n=5$. (Asterisks) $P<0.02$ rel to rtTA-miR-31 cells (no dox treat ent). (A Quantification of Bim immuno stochem 1 staining in 231 cell prip ry $\mathrm{m}$ nmary mors $56 \mathrm{~d}$ post-orthoto inject n. $n / 5$. (E) 231 cell lung netast es 54 oubsequent to orthotopic tro action, immunohistochemically stained fo phosp o-Akt. (F) Quantification of pho ho Akt staining in 231 cell pulmonary retastases $54 \mathrm{~d}$ following orthotopic implantation. $n=5$. (G) 231 cell lung hetastases $54 \mathrm{~d}$ after orthotopic introduction, immunohistochemically stained for Bim. (H) Quantification of Bim immunohistochemical staining in 231 cell pulmonary metastases $54 \mathrm{~d}$ post-orthotopic injection. $n=5$. All error bars represent mean \pm SEM.

To do so, we performe iv am astochemical staining on tissue sections der ed from orthotopically implanted animals bearing $n$ R-31-inducible 231 cells that re-expressed the various potential combinations of ITGA5, RDX, and RhoA.

The metastasis-specific attenuation of Akt function triggered by miR-31 induction could be partially reversed by re-expressing either ITGA5, RDX, or RhoA individually (Fig. 7E,F). However, concomitant restoration of ITGA5, RDX, and RhoA levels entirely prevented miR-31 activation from diminishing Akt signaling in pulmonary metastases (Fig. 7E,F). ITGA5, RDX, and RhoA failed to affect Akt activation in primary mammary tumors; moreover, ITGA5, RDX, and RhoA did not enhance Akt-dependent signaling in the lungs in 231 cells lacking miR-31 (Fig. 7E,F; Supplemental Fig. 26A). Hence, ITGA5, RDX, and RhoA were capable of collaborating to block the metastasis-specific inhibition of Akt signaling conferred by miR31 activation in pulmonary metastases.
Metastatic 231 cells in the lungs re-expressing either ITGA5 or RDX were partially impaired in their capacity to induce levels of the Bim protein following miR-31 induction (Fig. 7G,H). In addition, cells concurrently re-expressing ITGA5 and RDX completely failed to induce Bim protein levels in response to miR-31 activation (Fig. 7G,H). In contrast, RhoA had no effect on the ability of miR-31 induction to up-regulate Bim in metastatic cells (Fig. 7G,H). ITGA5, RDX, and RhoA failed to alter Bim protein levels in primary mammary tumors; also, ITGA5, RDX, and RhoA did not affect Bim expression in pulmonary metastases formed by 231 cells lacking miR-31 (Fig. 7G,H; Supplemental Fig. 26B). Hence, ITGA5 and RDX were able to antagonize the metastasis-specific stimulation of Bim protein levels mediated by acute miR-31 expression.

Collectively, the preceding observations revealed that signaling through the Akt and Bim pathways was perturbed by miR-31 activation in pulmonary metastases but not in primary mammary tumors. These metastasis-specific 
effects on signal transduction could be explained by miR31-dependent modulation of ITGA5, RDX, and RhoA.

\section{Discussion}

Truly effective therapeutic agents that block and/or reverse the process of tumor metastasis are urgently needed, as $>90 \%$ of human cancer deaths are attributable to metastatic disease (Gupta and Massagué 2006). In the present study, we demonstrated that acute activation of miR-31 in already-established breast cancer metastases elicits metastatic regression. These influences arise even when miR-31 is only briefly expressed in advanced macroscopic pulmonary metastases.

Our data indicate that acute expression of miR-31 in such metastases leads to induction of apoptosis within $1 \mathrm{~d}$ of activation. This apoptotic response precedes the overt metastatic regression triggered by acute miR-31 expression, which can only be observed beginning $2 \mathrm{~d}$ after dox administration. At this time, miR-31 has not yet succeeded in inducing cell cycle arrest in these metastatic foci. Accordingly, it appears that metastasis-specific apoptosis accounts for a significant proportion of miR-31's effects on already-established macroscopic lung metastases. At later time points after miR-31 induction, however, expression of this miRNA triggers both apoptosis and cytostasis. Consequently, the overall effects of miR-31 activation on already-seeded pulmonary metastase later time points seem to reflect the combined cytot ric and cytostatic influences of miR-31 inductio At pi ent, a mechanistic explanation for the rela vely elay kinetics of miR-31-imposed cytostasis re ains usive.

A substantial percentage of miR-31's actio on alm $y$ seeded lung metastases can be $\mathrm{m}$ ated th ough three particular downstream effectors th miRN. ITGA5, RDX, and RhoA. This implies hat cons utive activation of the signaling networks d , nnstream fro ITGA5, RDX, and RhoA may represen $\mathrm{me}$ is by which pulmonary metastases can acquire ro ance miR-31-conferred metastatic regressi

We note that $\mathrm{R}$-31 nduct antagonizes the persistence and outgrow $\mathrm{h}$ and $\mathrm{d}$-seeded metastases present in both the lungs an bone. In contrast, miR-31 activation fails to affect establis d liver metastases. These observations are consistent with the "seed and soil" model of metastatic colonization, which holds that disseminated tumor cells must make tissue-specific adaptations in order to survive and proliferate in various ectopic tissue microenvironments (Fidler 2003). Stated differently, they imply that miR-31's anti-metastatic activities derive, at least in part, from its ability to control downstream signaling networks involved in fostering critical interactions between disseminated tumor cells and the specific tissue microenvironments encountered at particular sites of metastasis.

In contrast to these effects on metastases, acute miR-31 expression does not affect the growth of primary mammary tumors. Such metastasis-specific influences imply that one or more components of the microenvironment encountered at certain metastatic sites impose constraints on survival and/or proliferation that are not present at the primary site of growth, once again echoing the "seed and soil" model (Fidler 2003). This notion is reinforced by the observation that even very large macroscopic pulmonary metastases respond quite differently to miR-31 activation than do comparably sized primary breast tumors.

Akt and Bim appear to represent two important signaling nodes that are altered in a metastasis-specific fashion in response to miR-31 induction. Currently, it is unclear why Akt function and Bim protein levels are not similarly responsive to miR-31 activation within the context of primary mammary tumors. We speculate that microenvironmental differences between orthotopic and ectopic sites of growth differentially impact the signaling outputs of the pathways controlled by these two proteins. Such organ-specific reliance nto survival pathways is not without precedent (apta and Massagué 2006). Interestingly, it has beep ree thed the expression of the Bimencoding mRN $/$ can $b$ antag nized via Akt-dependent inactivation of FOY $33 \mathrm{~A}$ ( anning and Cantley 2007). Thus, it $j \mathrm{po}$ ib that metastasis-specific induction of the Bir proten arises is a direct consequence of attenuate A activi i pulmonary metastases where miR31 has be acutely expressed.

th 23 ells and MCF7-Ras cells express constitutively activated alleles of the RAS oncogene. Therefore, we canno formally exclude the possibility that the antimetas tic effects observed upon miR-31 induction might only in breast carcinoma cells harboring constitutive Ras activation. However, our finding that acute miR81 expression fails to impact signaling through the Ras effector pathways involving MAPK and RalGEF strongly argues against the notion that miR-31 acts as a generic negative regulator of Ras-mediated transduction.

Altered expression of miR-31 has been observed in various human tumors. For example, we reported previously that miR-31 levels in primary human breast tumors are inversely associated with the propensity to suffer metastatic relapse (Valastyan et al. 2009b). Similarly, down-regulation of miR-31 was correlated with acquisition of an invasive phenotype by human bladder carcinomas (Wszolek et al. 2009). In addition, reduced miR-31 expression and/or homozygous deletion of the miR-31encoding genomic locus have been documented across a number of different human tumor types, although exceptions to this pattern of miR-31 down-regulation have also been described (Valastyan and Weinberg 2010).

Despite the fact that metastases are responsible for the overwhelming majority of carcinoma-associated mortality, most existing anti-cancer drugs are designed to reduce primary tumor burden. Moreover, those strategies intended to treat metastatic disease largely act by blocking initial tumor cell dissemination without affecting the proliferation and survival of already-established metastases (Steeg 2006; Smith and Theodorescu 2009). Indeed, a number of recently devised targeted agents designed to impair metastasis_-such as matrix metalloproteinase (MMP) inhibitors (Coussens et al. 2002), the Axl kinase inhibitor R428 (Holland et al. 2010), miR-10b antagonists (Ma et al. 2010), and the fascin inhibitor Migrastatin (Chen et al. 2010)-are 
thought to function principally by blocking tumor cell motility and invasion. If these anti-invasive agents fail to also impair the proliferation and survival of already-seeded metastases, then their ultimate clinical utility will be severely limited, as carcinoma patients often harbor numerous disseminated tumor cells at the time of initial clinical presentation (Gupta and Massagué 2006; Nagrath et al. 2007; Pantel et al. 2008). In this respect, the limited benefit observed in clinical trials involving MMP inhibitors is not encouraging (Coussens et al. 2002). Furthermore, preclinical studies with $\mathrm{R} 428$, miR-10b antagonists, and Migrastatin directly document a lack of efficacy against already-disseminated tumor cells (Holland et al. 2010; Ma et al. 2010; Oskarsson et al. 2010).

In contrast to these prior therapeutic targets, miR-31 can antagonize metastasis by impeding the proliferation and survival of already-disseminated tumor cells, including an ability to elicit regression of already-robustly growing macroscopic pulmonary metastases. Accordingly, these unique attributes of miR-31 function raise the possibility that intervention approaches centered on restoring miR-31 activity may prove useful for combating metastatic disease in certain human carcinomas, perhaps even in cases involving highly advanced macroscopic metastatic disease. Recently, several laboratories have described effective methodologies for delivering miRNA mimetics and miRNA-encoding genetic elements in vivo, although significant technological hurdles still remain (Kota et al. 2009; Takeshita et al. 2010; Trang et al. 2010; Wiggins et al. 2010). Thus, it may one day be possi ${ }^{1-1}$ to achieve effective delivery of miRNA mimetics t num $n$ tumors. Such technical advances, when couplo with he findings of the present study, would pro de cong impetus for further evaluation of the safe and eff acy of miR-31-based therapeutic agents.

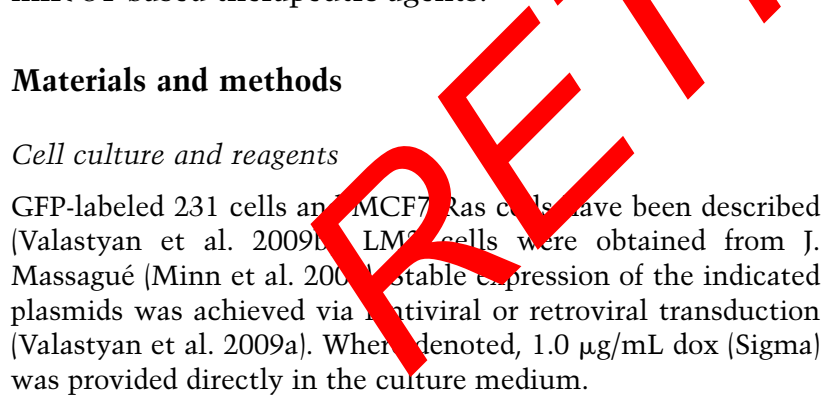

\section{Xenograft studies}

All animal studies complied with protocols approved by the Massachusetts Institute of Technology Committee on Animal Care. In the spontaneous metastasis assays, age-matched female nonobese diabetic severe combined immunodeficiency (NOD/ SCID) mice (propagated on-site) were injected bilaterally into the mammary fat pads with $1.0 \times 10^{6}$ cells resuspended in $1: 2$ Matrigel (BD Biosciences) plus normal growth media. Where denoted, these orthotopically arising primary tumors were surgically resected $1 \mathrm{mo}$ after implantation. In the experimental metastasis assays, age-matched male NOD/SCID mice were injected with $5.0 \times 10^{5}$ cells (resuspended in PBS) via the tail vein, or, instead, intracardiac injections were performed using $1.0 \times 10^{5}$ cells (resuspended in PBS). For all in vivo analyses, where in- dicated, dox was added to sucrose-supplemented $(10 \mathrm{mg} / \mathrm{mL})$ drinking water at a final concentration of $2.0 \mathrm{mg} / \mathrm{mL}$. The presence of established metastases at times of dox administration was confirmed by euthanizing in parallel mice that had been implanted with the exact same preparation of tumor cells; these mice carried metastases of the expected numbers and sizes. Metastasis was quantified at the indicated time points using a fluorescent dissecting microscope. In our studies, metastatic foci $<50 \mu \mathrm{m}$ in diameter were classified as micrometastases; macroscopic metastases were lesions $>50 \mu \mathrm{m}$ in diameter. Where specified, "large" macroscopic metastases were defined as lesions $>100 \mu \mathrm{m}$ in diameter, while "small" macroscopic metastases were foci with a diameter between $50 \mu \mathrm{m}$ and $100 \mu \mathrm{m}$.

\section{Immunohistochemistry}

Primary tumor and lung histolo embedded tissue sections . Immunohistochemical dect of Bim Cell Signaling), CD31 (Cell Signaling), cleay caspases Cell gnaling), cytokeratin14 (Santa Cruz Bioteck ology) Aucin anta Cruz Biotechnology), phosphorylated $\mathrm{kt}$ ho pho-Akt; Cell Signaling), phosphorylated extracely ar sig -regul d kinase (phospho-ERK; Cell Signaling) to horylat $\mathrm{lb}$ cone $\mathrm{H} 3$ (phospho-H3; Cell Signaling), or phospho lated $\mathrm{N} \kappa \mathrm{B}$ (phospho-NF-кB; Cell Signaling) was rmed on $10-\mu \mathrm{m}$ tissue sections using the indicated an oodies, Vectasta Elite ABC kits (Vector Laboratories), and In hPACT P $A B$ Substrate (Vector Laboratories) in accord with th manufact rers' instructions.

\section{iRNA in situ hybridization}

hiRnA expression was assessed from paraffin-embedded tissue sections using a protocol that we elaborated on previously (Valastyan et al. 2009b).

Expression analyses from human breast tumors

Microarray data from 295 primary human breast tumors (van de Vijver et al. 2002) were used to categorize tumors as ITGA5, RDX, and RhoA "high" or "low." Tumors were considered "high" or "low" if the normalized expression of all three of these mRNAs resided in the top or bottom $33 \%$ of tumors in this cohort, respectively.

\section{Statistical analyses}

Data are presented as mean \pm SEM. Unless otherwise noted, a Student's $t$-test was used for all comparisons, with $P<0.05$ considered statistically significant.

\section{Acknowledgments}

We thank Julie Valastyan for critical review of this manuscript; M. Saelzler, W. Guo, Z. Keckesova, and other members of the Weinberg laboratory for helpful discussions and materials; D. Bartel, G. Bokoch, S. Crouch, K. Hochedlinger, T. Kafri, S. Kuwada, J. Massagué, and P. Sharp for reagents; and the Koch Institute Histology Facility for tissue sectioning. This research was supported by the NIH, MIT Ludwig Center for Molecular Oncology, U.S. Department of Defense, and Breast Cancer Research Foundation. S.V. and R.A.W. are inventors on a patent application based in part on findings detailed in this manuscript. S.V. is a U.S. Department of Defense Breast Cancer Research Program Predoctoral Fellow. R.A.W. is an American Cancer Society Research Professor and a Daniel K. Ludwig Foundation Cancer Research Professor. 


\section{References}

Chen L, Yang S, Jakoncic J, Zhang JJ, Huang X. 2010. Migrastatin analogues target fascin to block tumour metastasis. Nature 464: 1062-1066.

Coussens LM, Fingleton B, Matrisian LM. 2002. Matrix metalloproteinase inhibitors and cancer: trials and tribulations. Science 295: 2387-2392.

Ebert MS, Neilson JR, Sharp PA. 2007. MicroRNA sponges: competitive inhibitors of small RNAs in mammalian cells. Nat Methods 4: 721-726.

Fidler IJ. 2003. The pathogenesis of cancer metastasis: the 'seed and soil' hypothesis revisited. Nat Rev Cancer 3: 453-458.

Grimson A, Farh KK, Johnston WK, Garrett-Engele P, Lim LP, Bartel DP. 2007. MicroRNA targeting specificity in mammals: determinants beyond seed pairing. Mol Cell 27: 91-105.

Gupta GP, Massagué J. 2006. Cancer metastasis: building a framework. Cell 127: 679-695.

Holland SJ, Pan A, Franci C, Hu Y, Chang B, Li W, Duan M, Tonreros A, Yu J, Heckrodt TJ, et al. 2010. R428, a selective small molecule inhibitor of Axl kinase, blocks tumor spread and prolongs survival in models of metastatic breast cancer. Cancer Res 70: 1544-1554.

Hüsemann Y, Geigl JB, Schubert F, Musiani P, Meyer M, Burghart E, Fomi G, Eils R, Fehm T, Riethmüller G, et al. 2008. Systemic spread is an early step in breast cancer. Cancer Cell 13: 58-68.

Kota J, Chivukula RR, O'Donnell KA, Wentzel EA, Montgomery CL, Hwang HW, Chang TC, Vivekanandan P, Torbenson M, Clark KR, et al. 2009. Therapeutic microRNA delixery suppresses tumorigenesis in a murine liver cancer $\mathrm{m}$ Cell 137: 1005-1017.

Ma L, Reinhardt F, Pan E, Soutschek J, Bhat B, M Teruya-Feldstein I, Bell GW, Weinberg RA. 2 . 0 . tic silencing of miR-10b inhibits metas sis in mou mammary tumor model. Nat Biotechne $28 \quad 34$

Manning BD, Cantley LC. 2007. Akt/PV signal navigating downstream. Cell 129: 1261-1274

Minn AJ, Gupta GP, Siegel PM, Bos PD, Shu V, Giri D D, Viale A, Olshen AB, Gerald WL, Mass aé J. 2005. enes that mediate breast cancer metastasis to ang. Iature 45 518-524.

Nagrath S, Sequist LV, Mahe varar, Bell DW, Irimia D, Ulkus L, Smith MR, Kwak FI Di arthy Syuzikansky A, et al. 2007. Isolation of are irc ting amour cells in cancer patients by mir ochip then Nature 450: 1235-1239.

Oskarsson T, Nago, y P IJ, Perez L, Mandal M, Yang G, Ouerfelli O, Xiao, Moore-MA, Massagué J, et al. 2010. Diverted total synt sis leads to the generation of promising cell-migration inhibi s for treatment of tumor metastasis: in vivo and mechanistic studies on the migrastatin core ether analog. I Am Chem Soc 132: 3224-3228.

Pantel K, Brakenhoff RH, Brandt B. 2008. Detection, clinical relevance and specific biological properties of disseminating tumour cells. Nat Rev Cancer 8: 329-340.

Smith SC, Theodorescu D. 2009. Learning therapeutic lessons from metastasis suppressor proteins. Nat Rev Cancer 9: 253-264.

Steeg PS. 2006. Tumor metastasis: mechanistic insights and clinical challenges. Nat Med 12: 895-904.

Takeshita F, Patrawala L, Osaki M, Takahashi RU, Yamamoto Y, Kosaka N, Kawamata M, Kelnar K, Bader AG, Brown D, et al. 2010. Systemic delivery of synthetic microRNA-16 inhibits the growth of metastatic prostate tumors via downregulation of multiple cell-cycle genes. Mol Ther 18: 181-187.

Trang P, Medina PP, Wiggins JF, Ruffino L, Kelnar K, Omotola M, Homer R, Brown D, Bader AG, Weidhaas JB, et al. 2010.
Regression of murine lung tumors by the let-7 microRNA. Oncogene 29: 1580-1587.

Valastyan S, Weinberg RA. 2009. MicroRNAs: crucial multitasking components in the complex circuitry of tumor metastasis. Cell Cycle 8: 3506-3512.

Valastyan S, Weinberg RA. 2010. miR-31: a crucial overseer of tumor metastasis and other emerging roles. Cell Cycle 9: 2124-2129.

Valastyan S, Benaich N, Chang A, Reinhardt F, Weinberg RA. 2009a. Concomitant suppression of three target genes can explain the impact of a microRNA on metastasis. Genes Dev 23: $2592-2597$.

Valastyan S, Reinhardt F, Benaich N, Calogrias D, Szász AM, Wang ZC, Brock JE, Richardson AL, Weinberg RA. 2009b. A pleiotropically acting microRNA, miR-31, inhibits breast cancer metastasis. Cell 1032-1046.

Valastyan S, Chang A, naich Reinhardt F, Weinberg RA. 2010. Concurrent s ppression $f$ integrin $\alpha 5$, radixin, and RhoA phenocop $s$ the ffects of hiR-31 on metastasis. Cancer Res 70: 5147153.

van de Vijver 1, He $>$, van cer LJ, Dai H, Hart AA, Voskuil DW, So"ren " Peterse JL, Roberts C, Marton MJ, et al. 2002 A gene pressi signature as a predictor of survival in ir st cance N $n g l$ J Med 347: 1999-2009.

Ventura A acks T. 009. MicroRNAs and cancer: short RNAs a long vay. Cell 136: 586-591.

Wiggins JF, Ru. ino L, Kelnar K, Omotola M, Patrawala L, Brown D, P der AG. 2010. Development of a lung cancer therapeutic $\mathrm{b}$ sed on the tumor suppressor microRNA-34. Cancer Res 70: $923-5930$.

rek MF, Rieger-Christ KM, Kenney PA, Gould JJ, Silva Neto B, Lavoie AK, Logvinenko T, Libertino JA, Summerhayes IC. 2009. A microRNA expression profile defining the invasive bladder tumor phenotype. Urol Oncol doi: 10.1016/j.urolonc. 2009.08.024. 


\section{Retraction}

Genes \& Development 23: 2592-2597 (2009)

\section{Concomitant suppression of three target genes can explain the impact of a microRNA on metastasis}

Scott Valastyan, Nathan Benaich, Amelia Chang, Ferenc Reinhardt, and Robert A. Weinberg

"Our study investigated the mechanisms by which miR-31 regulates different aspects of breast cancer metastasis. We have retracted our earlier publication involving miR-31 (Valastyan et al. 2009) because original data were compiled from different replicate experiments in order to assemble certain figure panels. As the same analytical methodology was used in this manuscript, we believe that the responsible course of action is to retract the article. We apologize for any inconvenience we have caused."

The cosigners of this retraction are the same set of coauthors as that of the Genes 4 Development article.

\section{Reference}

Valastyan S, Reinhardt F, Benaich N, Calogrias D, Szasz AM, Wang ZC, Brock JE, Richardson AL, Weinberg RA. 2009. A pleiotropically acting microRNA, miR-31, inhibits breast cancer metastasis. Cell 137: 1032-1046.

\section{Retraction}

Genes \& Development 25: 646-659 (2011)

\section{Activation of miR-31 function in already-established metastases elicits metastatic regression}

Scott Valastyan, Amelia Chang, Nathan Benaich, Ferenc Reinhardt, and Robert A. Weinberg

"Our study investigated the mechanisms by which miR-31 regulates different aspects of breast cancer metastasis. We have retracted our earlier publication involving miR-31 (Valastyan et al. 2009) because original data were compiled from different replicate experiments in order to assemble certain figure panels. As the same analytical methodology was used in this manuscript, we believe that the responsible course of action is to retract the article. We apologize for any inconvenience we have caused."

The cosigners of this retraction are the same set of coauthors as that of the Genes $\uplus$ Development article.

\section{Reference}

Valastyan S, Reinhardt F, Benaich N, Calogrias D, Szasz AM, Wang ZC, Brock JE, Richardson AL, Weinberg RA. 2009. A pleiotropically acting microRNA, miR-31, inhibits breast cancer metastasis. Cell 137: 1032-1046. 


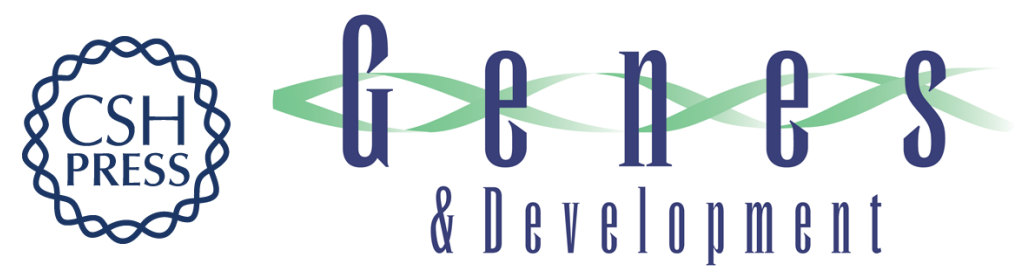

\section{Activation of miR-31 function in already-established metastases elicits metastatic regression}

Scott Valastyan, Amelia Chang, Nathan Benaich, et al.

Genes Dev. 2011, 25:

Access the most recent version at doi:10.1101/gad.2004211

\section{Supplemental http://genesdev.cshlp.org/content/suppl/2011/03/14/25.6.646.DC1 \\ Material}

Related Content

Activation of miR-31 function in already-established metastases elicits metastatic regression

Scott Valastyan, Amelia Chang, Nathan Benaich, et al.

Genes Dev. March , 2015 29: 686.2

References This article cites 27 articles, 5 of which can be accessed free at: http://genesdev.cshlp.org/content/25/6/646.full.html\#ref-list-1

Articles cited in:

http://genesdev.cshlp.org/content/25/6/646.full.html\#related-urls

\section{License}

Email Alerting

Service

Receive free email alerts when new articles cite this article - sign up in the box at the top right corner of the article or click here.

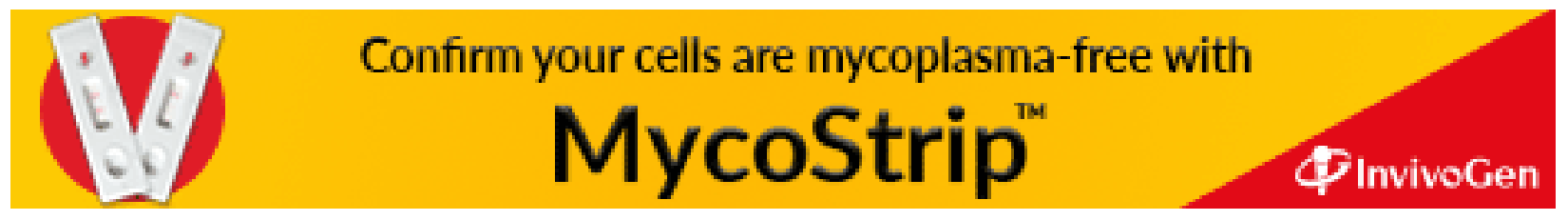

